Journal of Animal and Veterinary Advances 11 (14): 2373-2379, 2012

ISSN: $1680-5593$

(C) Medwell Journals, 2012

\title{
Inhibitory Effect of Crocin on Hepatic Steatosis in the Rats Fed with High Fat Diet
}

\author{
${ }^{1}$ Daryoush Mohajeri and ${ }^{2}$ Mehrdad Nazeri \\ ${ }^{1}$ Department of Veterinary Pathobiology, Tabriz Branch, Islamic Azad University, Tabriz, Iran \\ ${ }^{2}$ Department of Veterinary Medicine, Tabriz Branch, Islamic Azad University, Tabriz, Iran
}

\begin{abstract}
Non-Alcoholic Fatty Liver Disease (NAFLD) is now recognized as the most common type of liver disease and might lead to an important public health problem. The aim of the present study was to evaluate the protective effects of Crocin, a unique water-soluble glycosylated carotenoid in the stigmas of the Crocus sativus Linne and in the fruits of Gardenia jasminoides Ellis, on rat high fat diet-induced hepatic steatosis model. Male Wistar rats were given either control diet, high fat diet alone or high fat diet plus Crocin via gavage at different doses $(25,50$ and $100 \mathrm{mg} / \mathrm{kg} /$ day $)$ for 4 weeks in different experimental groups. The serum levels of Triglyceride (TG), Total Cholesterol (TC), Low-Density Lipoprotein (LDL-C), Very Low-Density Lipoprotein (VLDL-C) and High-Density Lipoprotein (HDL-C) were detected to determine deleterious metabolic effects. Aminotransferases, Alanine Aminotransferase (ALT) and Aspartate Aminotransferase (AST) were measured to determine hepatocyte injury. Alkaline Phosphatase (ALP) and bilirubin were measured to assess biliary function. Albumin was measured to reflect liver synthetic function. The lipid peroxidation product, Malondialdehyde (MDA) and reduced Glutathione (GSH) content was measured to assess free radical activity in the liver tissues. The enzymatic activities of Glutathione Peroxidase (GSH-Px), Superoxide Dismutase (SOD) and Catalase (CAT) were measured as indicators of antioxidation in liver tissue. Finally, the biochemical findings were matched with histopathological verifications. After 4 weeks, high fat diet caused deleterious metabolic effects including hypertriglyceridemia, hypercholesterolemia and liver dysfunction. Rats fed high fat diet alone showed increased activities of hepatocellular enzymes in plasma, significant decline in antioxidants and elevated lipid peroxidation indices in liver. Crocin treatment significantly reduced elevated markers of liver tissue injury and lipid peroxidation product (MDA) and brought back the liver antioxidants and the over accumulation lipids in serum towards normal. Histopathology of the liver confirmed the changes induced by high fat diet and the heptoprotective effect of Crocin. Crocin exerts protective effects against hepatic steatosis in rats fed with high fat diet possibly through its antioxidant actions.
\end{abstract}

Key words: High fat fed diet, crocin, antioxidants, hepatic steatosis, rats, Iran

\section{INTRODUCTION}

Non Alcoholic Fatty Liver Disease (NAFLD) as a global problem, human epidemics are usually afflicted and is associated with obesity, hyperlipidemia and type 2 diabetes mellitus. Research has shown that feed with high-fat diet leads to hepatic steatosis (Assy et al., 2000). Triglycerides and cholesterol are of important biological lipids of body that excess get them through the diet is resulted in hypertriglyceridemia (Hokanson, 2002; Kametani et al., 2002) and hypercholestrolemia (Walldius et al., 2004). NAFLD is diagnosed by accumulation of triglycerides in the hepatocytes in consequence of the esterification of free fatty acids and glycerol. Increase in free fatty acids in the liver is driven from three separate sources includes lipolysis (hydrolysis of glycerol and fatty acid from triglycerides) in adipose tissue, high fat diet and de novo lipogenesis (Postic and Girard, 2008). In contrast, fatty acids may used through $\beta$-oxidation, de novo esterification to triglycerides and store as fat droplets or excretion in the form of VLDL. Thus, accumulation of fat in the liver can occurs in results of increase the synthesis of fat, reduce in fat excretion or reduce in them oxidation. Donnelly et al. (2005) showed that $60 \%$ of liver triglyceride content is driven from influx of fatty acids from adipose tissue, $26 \%$ from de novo lipogenesis and 15\% from the diet (Donnelly et al., 2005). Nonalcoholic fatty liver is associated with some histopathologic changes which is different from steatosis to cirrhosis (Dixon et al., 2001; Angulo and Lindor, 2002; Clark et al., 2002; Farrell, 2003). It was formerly believed that steatosis is a simple phenomenon and has no complications. However, now a days it is known that fatty liver is vulnerable to factors such as oxidative stress and

Corresponding Author: Daryoush Mohajeri, Department of Veterinary Pathobiology, Tabriz Branch, Islamic Azad University, Tabriz, Iran 
can lead to Steatohepatitis which is associated with necrosis, inflammation, fibrosis and cirrhosis (James and Day, 1999; Orrenius et al., 2007). In the pathogenesis of nonalcoholic steatohepatitis is assumed that the accumulation of triglycerides in the liver or steatosis will yield to increases the susceptibility of liver to the damages caused by inflammatory cytokines and lymphokines, mitochondrial dysfunction and oxidative stress (Day, 2006; Day and James, 1998). Barbuio et al. (2007) showed that oxidative stress is effective in alteration of steatosis to steatohepatitis (Barbuio et al., 2007). However, although liver steatosis may lead to complete hepatic failure but appropriate and ideal treatment is not established (Angulo and Lindor, 2002). Biological materials with plant origin forms modern branch pharmacotherapy of disease. Although, various pharmacologic agents exist to treat various diseases but most patients cannot tolerate the side effects of chemical drugs from one hand and plants have very few side effects on patients from other hands. Obviously, it is necessary that several studies must be done on the new drugs in several stages before their entrance to the field of medicine. Crocin as a glycosylated carotenoid is an agent which has hypocholesterolemic and hypertriglyceridemic effects (He et al., 2005). Several studies have shown that Crocin has multiple pharmacologic effects such as protective effect against cardiovascular disease ( $\mathrm{He}$ et al., 2005; Shen and Qian, 2006; Xiang et al., 2006), preventive effect from proliferation of tumor cells (Magesh et al., 2006) neroprotective (Ahmad et al., 2005; Ochiai et al., 2004) and hepatoprotective (Tseng et al., 1995) effects. However, among the various protective mechanisms, the antioxidant activity of Crocin is considered responsible for its pharmacological effects (Magesh et al., 2006). By consideration of antioxidant and hypolipidemic (Sheng et al., 2006) effects of crocin, this matter it will probably be able to protect the liver from steatosis. However, no studies concerning the effect of crocin on the liver steatosis in high fat diet fed-rats are available in the literature. This study examined the hypothesis that crocin supplementation prevents liver steatosis in a high fat diet model. The results of this study demonstrate that crocin supplementation prevents liver steatosis and decreases oxidative stress in hepatocytes exposed to high levels of lipid.

\section{MATERIALS AND METHODS}

This study carried out during 2010 in the research center of Islamic Azad University. All procedures were conducted under supervision of Animal Rights Monitoring Committee of Islamic Azad University Research Center.
Animals: Sixty male Wistar rats, weighted $180 \pm 20 \mathrm{~g}$ and aged 9 weeks old were obtained from the animal breeding center of Islamic Azad University. The rats were divided into 6 equal groups of 10 animals including: normal control, normal rats fed high-fat diets, normal rats fed high-fat diets plus Clofubrate, 4-6 rats which are fed high-fat diets plus different levels of Crocin $(25,50$ and $100 \mathrm{mg} / \mathrm{kg} /$ day). Management and husbandry conditions were identical in all groups with $12 / 12 \mathrm{~h}$ light/dark cycle at $21 \pm 2^{\circ} \mathrm{C}$. Food and water were provided ad libitum.

Experimental plan: In rats were fed with high-fat diets used of high-fat emulsion which its formula is shown in Table 1, to induce hepatic steatosis based on Zou et al. (2006) Method. All treatment groups received high-fat emulsion at the dose of $10 \mathrm{~mL} \mathrm{~kg} \mathrm{~kg}^{-1}$ daily at morning 8 o'clock for 4 weeks. Simultaneously, control group received normal saline in same dosage. Rat's of groups 4-6 beside of high-fat emulsion received Crocin at the dose of 25,50 and $100 \mathrm{mg} / \mathrm{kg} /$ day. Group 3 beside of high-fat emulsion received Clofubrate at the dose of $320 \mathrm{mg} / \mathrm{kg} /$ day through gavage as suspension in the $2 \mathrm{~mL} \mathrm{~kg}^{-1}$ methylcellulose $0.5 \%$ (Sheng et al., 2006). Control group received $2 \mathrm{~mL} \mathrm{~kg}^{-1}$ methylcellulose $5 \%$.

Biochemical factors evaluation: At the end of the experiment, blood samples were collected from the retroorbital plexus and the sera prepared through centrifuging at $2500 \times \mathrm{g}$ for $15 \mathrm{~min}$ at $30^{\circ} \mathrm{C}$. After $12 \mathrm{~h}$ fasting, blood glucose and serum biomarkers of liver function including ALT, AST (Reitman and Frankel, 1957), LDH(Martinek, 1972), albumin, TP (Lowry et al., 1951) and total bilirubin (Malloy and Evelyn, 1937) were measured using commercially available kits.

Measurement of antioxidant activity: All experimental rats were euthanized by cervical dislocation. The rat's liver were removed immediately and washed in normal saline and homogenate $10 \%$ prepared in $1.15 \% \mathrm{w} / \mathrm{v}$ of potassium chloride. The homogenate was centrifuged in $7000 \times \mathrm{g}$ for $10 \mathrm{~min}$ at $4^{\circ} \mathrm{C}$ and supernatant were used for measurement

\begin{tabular}{lr} 
Table 1: Composition of high-fat emulsion gavaged to rats & \\
\hline Constituents & Amount \\
\hline Corn oil & $400.0 \mathrm{~g}$ \\
Sacarose & $150.0 \mathrm{~g}$ \\
Milk powder & $80.0 \mathrm{~g}$ \\
Cholesterol & $100.0 \mathrm{~g}$ \\
Sodium deoxy colat & $10.0 \mathrm{~g}$ \\
Tween 80 & $36.4 \mathrm{~g}$ \\
Propilen glikol & $31.1 \mathrm{~g}$ \\
Multi vitamin & $2.5 \mathrm{~g}$ \\
Salt & $10.0 \mathrm{~g}$ \\
Minerals & $1.5 \mathrm{~g}$ \\
Normal saline & $300.0 \mathrm{~mL}$ \\
\hline
\end{tabular}


of oxidative stress by determination of Malondialdehyde (MDA) as well as Antioxidant Enzymes (AOE) such as Superoxide Dismutase (SOD), Catalase (CAT), Glutathione Peroxidase (GSH-PX) and glutathione reductase. MDA, SOD, CAT and GSH-PX, GR were measured by using commercially available kits according to the manufacture's protocol (Nanjing Jiancheng Bioengineering Institute, Nanjing, China). Liver homogenate MDA levels were expressed as nmol MDA per mg protein and antioxidant activity was expressed as arbitrary units per $\mathrm{mg}$ protein.

Degree of lipid peroxidation in kidney tissue homogenates was determined in terms of Thiobarbituric Acid Reactive Substances (TBARSs) formation by following the protocol of Esterbauer and Cheeseman (1990). SOD activity was measured by Nishikimi Method (Nishikimi et al., 1972) and was modified by Kakkar Method (Kakkar et al., 1984). Each unit of SOD activity was determined as required enzyme concentration for prohibition of creation color at $1 \mathrm{~min}$, under study conditions. CAT activity was measured by Claiborne Method (Clairborne, 1986) and was based on hydrogen peroxide breakdown. GPX activity was measured by Rotruck Method (Rotruck et al., 1973) and was expressed as micromole of GSSG/minute/milligram of protein, based on blew reaction:

$$
2 \mathrm{H}_{2} \mathrm{O}+\mathrm{GSSG} \rightarrow \mathrm{H}_{2} \mathrm{O}_{2}+2 \mathrm{GSH}
$$

GR activity was measured by Mohandas Method (Mohandas et al., 1984) based on blew reaction:

$$
\mathrm{NADPH}+\mathrm{H}^{+}+\mathrm{GSSG} \rightarrow \mathrm{NADP}^{+}+2 \mathrm{GSH}
$$

Microscopic studies: A small piece of hepatic tissue from the anterior portion of the left lateral lobe was removed for histological analysis. The sample was fixed by immersing it in 10\% neutral-buffered formalin. The sample was then embedded in paraffin, sliced into $5 \mu \mathrm{m}$ sections and stained with hematoxylin-eosin for blinded histological assessment (Lee and Luna, 1968). Hepatocytes were assayed from fatty changes aspect like a mentioned method by Burt et al. (1998) and Wang et al. (2009) and steatosis were degreed from $0-4$ ( 0 : without steatosis, 1 : $<25 \%$ steatosis, 2: approximately $26-50 \%$ steatosis, 3 : approximately $51-75 \%$ steatosis, $4:>76 \%$ steatosis). The stained $5 \mu \mathrm{m}$ sections were graded as follows: 0 , absent; I, minimal; II, mild; II, modest; IV, severe. The histological changes were evaluated in nonconsecutive, randomly chosen x200 histological fields using light microscope, NIKON ECLIPSE E200 (Shen et al., 2009).

Statistical analysis: The Statistical Package for Social Sciences (SPSS Inc., Chicago, I, USA), Version 13.0 was used for statistical analysis. All data are presented as mean \pm SEM. Before statistical analysis, all variables were checked for normality and homogeneity of variance by using the Kolmogorov-Smirnoff and Levene tests, respectively. The data obtained were tested by ANOVA followed by Tukey's post-hoc multiple comparison test. $\mathrm{p}<0.05$ was considered statistically significant.

\section{RESULTS AND DISCUSSION}

Effect of Crocin on the biochemical parameters of liver damage caused by feeding high-fat diet: In Group $2, A L T$, AST, ALP and TB increased and TP and Alb decreased significantly in compared with control group $(\mathrm{p}<0.01)$. In Group 3 and 6, high levels of ALT, AST, ALP and TB decreased to normal levels and levels of TP and Alb increased to their normal boundaries $(\mathrm{p}<0.01)$. In Group 5 , levels of ALT, AST, ALP and TB decreased and levels of $\mathrm{TP}$ and $\mathrm{Alb}$ increased but not reached to normal levels $(\mathrm{p}<0.05)$. In Group 4 no significant changes observed (Table 2).

Histopathological findings: In microscopic studies no abnormalities was found in the livers of control group rats (Fig. 1A). But in Group 2 rats' which fed with high-fat diet for 4 weeks, sever steatosis was found as micro and macrovesicular fatty changes accompanied hepatitis (Fig. 1B). Clofubrate prevent from steatosis in Group 3 rats

Table 2: Effect of Crocin on serum biochemical parameters in hepatic steatosis consequence of high-fat diet

\begin{tabular}{|c|c|c|c|c|c|c|}
\hline Groups & $\mathrm{ALT}\left(\mathrm{UL} \mathrm{L}^{-1}\right)$ & $\operatorname{AST}\left(\mathrm{UL}^{-1}\right)$ & $\mathrm{ALP}\left(\mathrm{IU} \mathrm{L}^{-1}\right)$ & $\mathrm{TB}\left(\mathrm{Mg} \mathrm{dL}^{-1}\right)$ & $\operatorname{ALB}\left(\mathrm{g} \mathrm{dL}^{-1}\right)$ & $\mathrm{TP}\left(\mathrm{g} \mathrm{dL}^{-1}\right)$ \\
\hline 1 (control) & $54.82 \pm 2.36^{\text {bde }}$ & $68.90 \pm 1.71^{\mathrm{bde}}$ & $194.87 \pm 9.03^{\text {bde }}$ & $0.81 \pm 0.03^{\text {bde }}$ & $4.38 \pm 0.42^{\text {bde }}$ & $8.28 \pm 0.58^{\text {bde }}$ \\
\hline 2 (high-fat diet) & $71.25 \pm 3.12^{\mathrm{acef}}$ & $93.21 \pm 2.96^{\mathrm{acef}}$ & $281.67 \pm 11.25^{\text {acef }}$ & $1.29 \pm 0.07^{\mathrm{acef}}$ & $3.12 \pm 0.21^{\text {acef }}$ & $5.56 \pm 0.45^{\text {acef }}$ \\
\hline 3 (high-fat diet + Clofubrate) & $55.90 \pm 2.47^{\mathrm{bd}}$ & $68.21 \pm 1.34^{\mathrm{bd}}$ & $208.92 \pm 8.09^{b d}$ & $0.87 \pm 0.06^{\mathrm{bd}}$ & $4.32 \pm 0.36^{\mathrm{bd}}$ & $7.26 \pm 0.47^{\mathrm{bd}}$ \\
\hline 4 (high-fat diet+Crocin $25 \mathrm{mg} \mathrm{kg}^{-1}$ ) & $69.55 \pm 3.32^{\text {acf }}$ & $89.76 \pm 3.24^{\mathrm{acf}}$ & $275.61 \pm 9.65^{\text {acf }}$ & $1.25 \pm 0.06^{\mathrm{acf}}$ & $3.33 \pm 0.27^{\text {acf }}$ & $5.65 \pm 0.42^{\mathrm{acf}}$ \\
\hline 5 (high-fat diet + Crocin $50 \mathrm{mg} \mathrm{kg}^{-1}$ ) & $62.56 \pm 2.95^{\mathrm{ab}}$ & $78.30 \pm 2.61^{a b}$ & $235.62 \pm 6.91^{\mathrm{sb}}$ & $1.06 \pm 0.05^{\mathrm{ab}}$ & $3.73 \pm 0.29^{\mathrm{ab}}$ & $6.16 \pm 0.43^{\mathrm{ab}}$ \\
\hline 6 (high-fat diet + Crocin $100 \mathrm{mg} \mathrm{kg}^{-1}$ ) & $56.30 \pm 2.64^{\text {bd }}$ & $69.91 \pm 2.15^{\mathrm{bd}}$ & $214.88 \pm 8.50^{\text {bd }}$ & $0.85 \pm 0.40^{b d}$ & $4.31 \pm 0.34^{\mathrm{bd}}$ & $7.21 \pm 0.52^{\text {bd }}$ \\
\hline ANOVA & $\mathrm{p}=0.000$ & $p=0.000$ & $\mathrm{p}=0.000$ & $\mathrm{p}=0.000$ & $\mathrm{p}=0.000$ & $\mathrm{p}=0.000$ \\
\hline
\end{tabular}
Biochemical parameters

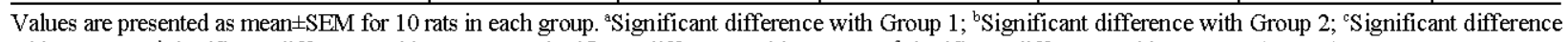

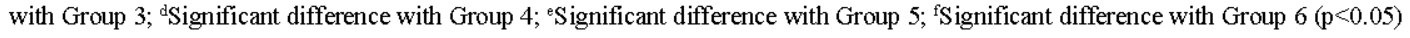




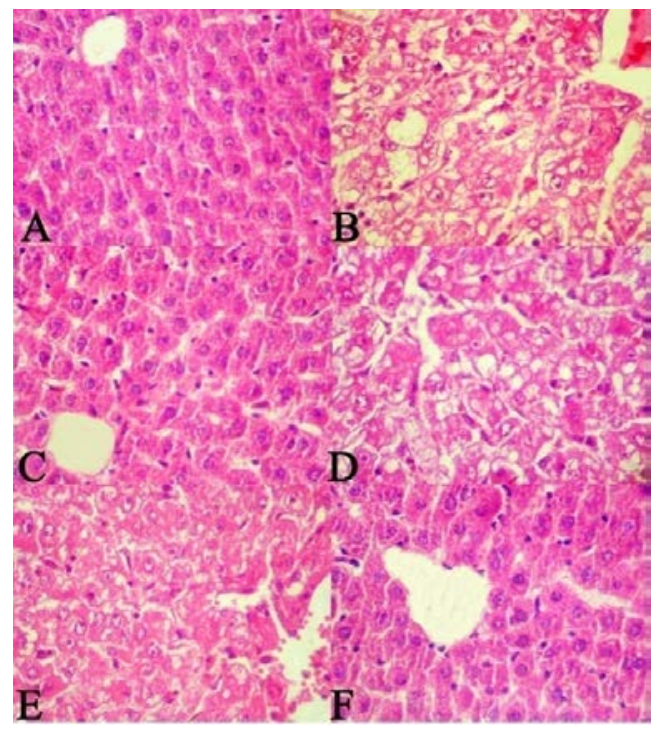

Fig. 1: A) Control group; B) High-fat diet group; C) Highfat diet + Clofubrate; D) High-fat diet + Crocin $25 \mathrm{mg} \mathrm{kg}^{-1}$; E) High-fat diet + Crocin $50 \mathrm{mg} \mathrm{kg}^{-1}$ and F) High-fat diet + Crocin $100 \mathrm{mg} \mathrm{kg}^{-1}$. H\&E 40x

Table 3: Effect of Crocin on the hepatic steatosis in rats fed high-fat diet

\begin{tabular}{lcccccc}
\hline & \multicolumn{7}{c}{ Hepatic steatosis grading } & & & \\
Groups & 0 & 1 & 2 & 3 & 4 & p-value \\
\hline 1 & 10 & 0 & 0 & 0 & 0 & \\
2 & 0 & 0 & 1 & 2 & 7 & $\mathrm{~d}$ \\
3 & 5 & 3 & 2 & 0 & 0 & $\mathrm{~b}$ \\
4 & 0 & 1 & 1 & 3 & 5 & $\mathrm{c}$ \\
5 & 1 & 3 & 5 & 1 & 0 & ac \\
6 & 5 & 2 & 3 & 0 & 0 & b \\
\hline
\end{tabular}

Each group contains 10 rats. ${ }^{a} p<0.05 ;{ }^{b} p<0.01$ in compared with groups fed high-fat diet. ${ }^{c} p<0.05 ;{ }^{d} p<0.01$ in compared with control group

(Fig. 1C). In Group 5 and 6, Crocin prevent from fatty changes in hepatocytes as dose-dependently (Fig. 1F and E). But in Group 4, Crocin cannot prevent from steatosis (Fig. 1D).

Figure 2 shows microscopic view of hepatic tissue stained by Oil Red-O Method. Effect of Crocin on the pathologic grading of hepatic steatosis in rats fed high-fat diet is shown in Table 3 .

Effect of Crocin on metabolism of fat due to high-fat diet: Clofubrate and Crocin in Group 3 and 6 significantly decreased markedly increased serum levels of TG, total cholesterol, LDL and VLDL compared with Group 2 $(\mathrm{p}<0.001)$ and significantly increased slightly decreased serum levels of HDL than Group $2(\mathrm{p}<0.01)$. In Group 5 , Crocin significantly decreased serum levels of total cholesterol, LDL and VLDL compared with Group 2

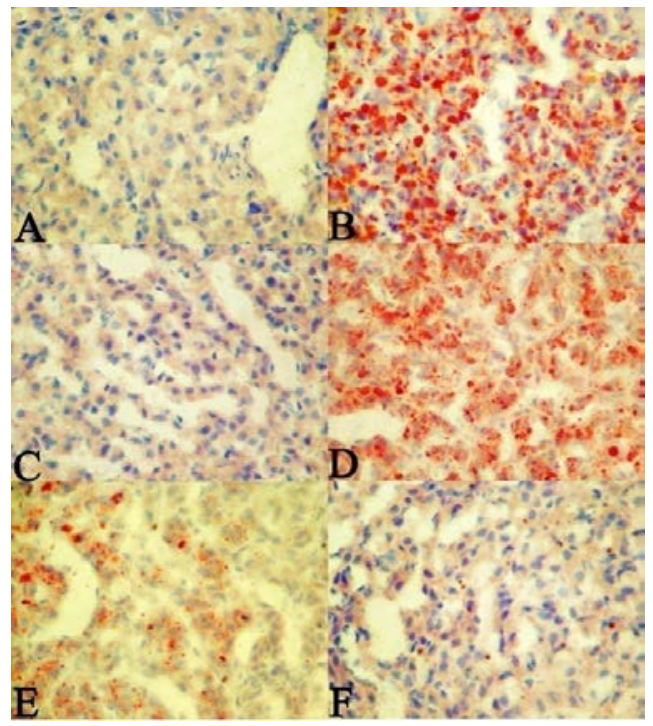

Fig. 2: A) Control group; B) High-fat diet group; C) High-fat diet + Clofubrate; D) High-fat diet+Crocin $25 \mathrm{mg} \mathrm{kg}^{-1}$; E) High-fat diet + Crocin $50 \mathrm{mg} \mathrm{kg}^{-1}$ and F) High-fat diet + Crocin $100 \mathrm{mg} \mathrm{kg}^{-1}$. Oil redO staining $40 \mathrm{x}$

$(\mathrm{p}<0.01)$ and significantly increased serum levels of $\mathrm{HDL}$ than Group $2(\mathrm{p}<0.05)$. In Group 4, Crocin can significantly decrease serum levels of total cholesterol, LDL and VLDL compared with Group $2(\mathrm{p}<0.05)$ but cannot significantly increase serum levels of HDL than Group 2 (Table 4).

Effect of Crocin on anti-oxidative activity of liver in damage induced by high fat diet: In Group 2 , Hepatic levels of antioxidant enzymes superoxide dismutase, catalase, glutathione peroxidase and glutathione reductase compared with Group 1 (normal control), significantly reduced $(\mathrm{p}<0.01)$ and the levels of malondialdehyde significantly increased $(\mathrm{p}<0.01)$. Clofubrate and Crocin in Group 3 and 6 significantly increased markedly decreased levels of SOD, CAT, GPX and GR compared with Group $2(\mathrm{p}<0.01)$ and significantly decreased slightly increased levels of malondialdehyde than Group $2(\mathrm{p}<0.01)$ (Table 5).

The increased activities of marker enzymes, AST, ALT and ALP are suggestive of liver injury (Chidambarama and Venkatraman, 2010). Because these serum liver biomarkers disorders have been documented in hepatic steatosis (Angulo, 2002; Wang et al., 2009; Chidambarama and Venkatraman, 2010), their levels were studied. Increased plasma activities of AST, ALT and ALP were found in high fat diet fed rats indicating 
Table 4: Effect of Crocin on lipid levels in rats fed high-fat diet

\begin{tabular}{llllll}
\hline Groups & TG $\left(\mathrm{mg} \mathrm{L}^{-1}\right)$ & Total cholesterol $\left(\mathrm{mg} \mathrm{L}^{-1}\right)$ & $\mathrm{LDL}\left(\mathrm{mg} \mathrm{L}^{-1}\right)$ & VLDL $\left(\mathrm{mg} \mathrm{L}^{-1}\right)$ & $\left.\mathrm{HDL}^{-} \mathrm{mg} \mathrm{L}^{-1}\right)$ \\
\hline 1 & $93.62 \pm 4.26$ & $86.90 \pm 3.62$ & $15.77 \pm 0.83$ & $17.65 \pm 1.12$ & $53.48 \pm 3.22$ \\
2 & $238.55 \pm 6.95$ & $221.39 \pm 7.86$ & $124.90 \pm 4.75$ & $47.62 \pm 2.18$ & $48.87 \pm 2.30$ \\
3 & $100.85 \pm 3.47^{\mathrm{c}}$ & $112.51 \pm 4.34^{\mathrm{c}}$ & $27.62 \pm 1.09^{\mathrm{c}}$ & $28.51 \pm 1.06^{\mathrm{c}}$ & $56.38 \pm 4.34^{\mathrm{b}}$ \\
4 & $213.75 \pm 6.38^{\mathrm{a}}$ & $193.56 \pm 6.24^{\mathrm{a}}$ & $101.61 \pm 4.65^{\mathrm{a}}$ & $41.62 \pm 2.56^{\mathrm{a}}$ & $50.33 \pm 0.27$ \\
5 & $178.56 \pm 5.35^{\mathrm{b}}$ & $138.30 \pm 4.61^{\mathrm{b}}$ & $51.72 \pm 3.71^{\mathrm{b}}$ & $32.15 \pm 2.15^{\mathrm{b}}$ & $54.43 \pm 3.29^{\mathrm{a}}$ \\
6 & $95.30 \pm 2.64^{\mathrm{c}}$ & $91.89 \pm 4.15^{\mathrm{c}}$ & $16.78 \pm 1.25^{\mathrm{c}}$ & $17.68 \pm 2.15^{\mathrm{c}}$ & $57.43 \pm 2.34^{\mathrm{b}}$ \\
ANOVA & $\mathrm{p}=0.000$ & $\mathrm{p}=0.000$ & $\mathrm{p}=0.000$ & $\mathrm{p}=0.000$ & $\mathrm{p}=0.000$ \\
\hline
\end{tabular}

Values are presented as mean \pm SEM for 10 rats in each group. ${ }^{a} \mathrm{p}<0.05 ;{ }^{b} \mathrm{p}<0.01 ;{ }^{\mathrm{c}} \mathrm{p}<0.001$

Table 5: Effect of Crocin on anti-oxidative activity of rat livers in steatosis induced by high fat diet Biochemical parameters

\begin{tabular}{|c|c|c|c|c|c|}
\hline Groups & MDA (nmol g ${ }^{-1}$ protein) & $\mathrm{SOD}\left(\mathrm{U} \mathrm{mg}^{-1}\right.$ protein) & $\mathrm{CAT}\left(\mathrm{U} \mathrm{mg}^{-1}\right.$ protein) & GPX (U mg ${ }^{-1}$ protein) & $\mathrm{GR}\left(\mathrm{U} \mathrm{mg}^{-1}\right.$ protein) \\
\hline 1 & $3.54 \pm 0.16^{\text {bde }}$ & $13.64 \pm 0.54^{\text {bde }}$ & $64.66 \pm 2.13^{\text {bde }}$ & $22.84 \pm 1.65^{\text {bde }}$ & $123.37 \pm 5.65^{\text {bde }}$ \\
\hline 2 & $5.18 \pm 0.21^{\text {acef }}$ & $9.13 \pm 0.32^{\text {acef }}$ & $41.74 \pm 1.15^{\text {acef }}$ & $17.49 \pm 0.83^{\text {acef }}$ & $88.85 \pm 3.52^{\text {acef }}$ \\
\hline 3 & $3.59 \pm 0.18^{\mathrm{bd}}$ & $12.53 \pm 0.52^{\mathrm{bd}}$ & $60.84 \pm 1.74^{\mathrm{bd}}$ & $21.95 \pm 1.54^{\mathrm{bd}}$ & $116.13 \pm 3.42^{\mathrm{bd}}$ \\
\hline 4 & $5.15 \pm 0.26^{\mathrm{acf}}$ & $9.33 \pm 0.63^{\text {acf }}$ & $43.12 \pm 1.16^{\text {acf }}$ & $18.12 \pm 0.94^{\mathrm{acf}}$ & $90.26 \pm 3.72^{\mathrm{acf}}$ \\
\hline 5 & $4.86 \pm 0.28^{\mathrm{ab}}$ & $10.74 \pm 0.47^{\mathrm{ab}}$ & $52.14 \pm 1.85^{a b}$ & $19.12 \pm 1.14^{\mathrm{ab}}$ & $106.57 \pm 3.12^{\mathrm{ab}}$ \\
\hline 6 & $3.62 \pm 0.19^{b d}$ & $12.59 \pm 0.53^{\text {bd }}$ & $62.12 \pm 1.81^{\mathrm{bd}}$ & $20.35 \pm 1.34^{\mathrm{bd}}$ & $118.32 \pm 4.02^{\text {bd }}$ \\
\hline ANOVA & $p=0.000$ & $\mathrm{p}=0.000$ & $\mathrm{p}=0.000$ & $\mathrm{p}=0.000$ & $\mathrm{p}=0.000$ \\
\hline
\end{tabular}

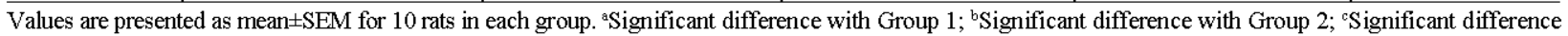

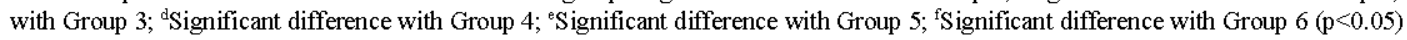

damage to liver cells. These results were consistent with the findings reported by Chidambarama and Venkatraman (2010). Treatment with Crocin notably prevented the elevation of these enzymes to an extent that was comparable to the Clofibrate. These results are in line with the findings reported by El-Maraghy who observed the hepatoprotective action of crocin in iron overload-treated rats (El-Maraghy et al., 2009).

The biochemical findings were matched with histopathological verification. Rats fed with high-fat emulsion for 4 weeks developed a higher degree of steatosis. Howevere, histopathological assessment of liver tissues from high fat emulsion induced rat hepatic steatosis, displayed the antihepatosteatosis effects of crocin. Administration of crocin resulted in prevention of hepatic fatty deposition in hepatocytes. Especially, crocin at the dose of $100 \mathrm{mg} \mathrm{kg}^{-1}$ almost blocked the formation of steatosis. Histopathological changes in agreement with biochemical findings were concordant with those of previously reported (Wang et al., 2009).

The results show that high fat diet caused significant decreases in SOD, CAT, Gpx and GR activities. The derangement in enzymatic antioxidant potential indicates that high fat diet fed rats are unable to cope up with excess free-radical formation which lead to tissue damage. A body of evidence indicates that accumulation of fat in the liver increases the susceptibility to other insults such as oxidative stress that results in the progression of steatosis to steatohepatitis, fibrosis and cirrhosis (Koteish and Diehl, 2002). Considering the recently recognized association between oxidative stress and inflammation (Chidambarama and Venkatraman, 2010), the present experiment confirms that high fat diet could result in oxidative liver injury. Induction of oxidative stress is evident from the increased peroxidation marker (MDA) and inadequate antioxidant enzymes status in liver of rats fed high fat diet. Researchers estimated antioxidant activities of crocin by determination of hepatic MDA content and antioxidant enzymes activity. High fat diet fed caused an increase in liver MDA content but a decrease in liver antioxidant enzymes activity compared with normal control group. Crocin supplementation significantly improved the antioxidant defense mechanisms in high fat diet fed rats in a concentration-dependent manner among the tested doses.

These results suggest that the imbalance between oxidative stress generation and antioxidants formation could occur after high fat diet fed and crocin could prevent this pathological process indicating its therapeutic and preventive effect on hepatosteatosis induced by high fat ingestion. Antioxidant activity of crocin is concordant with those of other investigators (Hosseinzadeh et al., 2009; Chen et al., 2008). The results of biochemical tests together with histological observations suggest that crocin treatment lowers steatosis and prevents peroxidative damage and the effects are comparable with that of Clofibrate.

To analyze the possible role of Crocin in lipid metabolism which is the key factor in fatty liver formation, serum TG, TC, VLDL-C, HDL-C and LDL-C were investigated. After 4 weeks of treatment, the serum levels of TG, TC, VLDL-C andLDL-C was markedly increased in the high fat diet fed group compared to those in the control group. This finding was parallel to the previous study (Zou et al., 2006). Treatment of high fat diet fed rats with crocin showed considerable restoration of lipid levels to that of control. The increased serum levels of TG, TC, 
VLDL-C and LDL-C were significantly suppressed whereas the decreased serum HDL-C level was obviously elevated by crocin treatment in high fat diet fed rat.

Results of the histological changes in high fat diet rats, widespread deposition of lipid droplets inside the parenchymal cells are consistent with the result of the biochemical analysis. This result suggests that crocin can prevent hepatosteatosis via downregulation of accumulation of lipid in serum and liver. Liver plays a key role in lipid metabolism. Hepatic steatosis refers to the excessive accumulation of lipids within hepatocytes due to imbalance between lipid formation and lipid degradation (Burt et al., 1998). Hypercholesterolaemia, hypertriglyceridaemia, low level of HDL-C and high level of LDL-C are the most common impairments in lipid homeostasis in patients with steatosis (Angulo and Lindor, 2002). Previous study has showed crocin has hypolipidemic effects (Sheng et al., 2006). In this study, crocin significantly improved both the biochemical and histological evidence of hepatic lipid accumulation. These results indicate that crocin attenuates the disorder of lipid metabolism in liver resulted from high fat diet fed.

\section{CONCLUSION}

This study reveals that Crocin as a glycosylated carotenoid contained in the stigmas of Crocus sativus Linne and in the fruits of Gardenia jasminoides Ellis, prevents high fat fed induced accumulation of lipid in rat liver. The preventive effect of Crocin is mediated through downregulation the levels of TG, TC, VLDL-C and LDL-C and elevation HDL-C synthesis. These changes are associated with decreasing in serum biomarkers of hepatic injury as well as attenuation of oxidative stress formation by Crocin treatment. These results demonstrate that crocin has preventive effects against high fat diet induced rat fatty liver. It is noteworthy that this experiment has been performed on animal, so further studies are needed to examine whether similar findings would be obtained in humans.

\section{REFERENCES}

Ahmad, A.S., M.A. Ansari, M. Ahmad, S. Saleem, S. Yousuf, M.N. Hoda and F. Islam, 2005. Neuroprotection by crocetin in a hemi-parkinsonian rat model. Pharmacol. Biochem. Behav., 81: 805-813.

Angulo, P. and K.D. Lindor, 2002. Non-alcoholic fatty liver disease. J. Gastroenterol. Hepatol., 17: S186-S190.
Angulo, P., 2002. Non-alcoholic fatty liver disease. New Engl. J. Med., 346: 1221-1231.

Assy, N., K. Kaita, D. Mymin, C. Levy, B. Rosser and G. Minuk, 2000. Fatty infiltration of liver in hyperlipidemic patients. Dig. Dis. Sci., 45: 1929-1934.

Barbuio, R., M. Milanski, M.B. Bertolo, M.J. Saad and L.A. Vellosa, 2007. Infliximab reverses steatosis and improves insulin signal transduction in liver of rats fed a high-fat diet. J. Endocrinol., 194: 539-550.

Burt, A.D., A. Mutton and C.P. Day, 1998. Diagnosis and interpretation of steatosis and steatohepatitis. Semin. Diagn. Pathol., 15: 246-258.

Chen, Y., H. Zhang, X. Tian, C. Zhao and L. Cai et al., 2008. Antioxidant potential of crocins and ethanol extracts of Gardenia jasminoides ELLIS and Crocus sativus L.: A relationship investigation between antioxidant activity and crocin contents. Food Chem., 109: 484-492.

Chidambarama, J. and A.C. Venkatraman, 2010. Cissus quadrangularis stem alleviates insulin resistance, oxidative injury and fatty liver disease in rats fed high fat plus fructose diet. Food Chem. Toxicol., 48: 2021-2029.

Clairborne, A., 1986. Catalase Activity. In: Handbooks for Methods for Oxygen Radical Research, Greenwald, R.A. (Ed.). CRC Press Inc., Boca Raton, FL, pp: 283-284.

Clark, J.M., F.L. Brancati and A.M. Diehl, 2002. Nonalcoholic fatty liver disease. Gastroenterology, 122: 1649-1657.

Day, C.P. and O.F.W. James, 1998. Steatohepatitis: A tale of two 'hits'. Gastroenterology, 114: 842-845.

Day, C.P., 2006. From fat to inflammation. Gastroenterology, 130: 207-210.

Dixon, J.B., P.S. Bhathal and P.E. O'Brien, 2001. Nonalcoholic fatty liver disease: Predictors of nonalcoholic steatohepatitis and liver fibrosis in the severely obese. Gastroenterology, 121: 91-100.

Donnelly, K.L., C.I. Smith, S.J. Schwarzenberg, J. Jessurun, M.D. Boldt and E.J. Parks, 2005. Sources of fatty acids stored in liver and secreted via lipoproteins in patients with nonalcoholic fatty liver disease. J. Clin. Invest., 115: 1343-1351.

El-Maraghy, S.A., S.M. Rizk and M.M. El-Sawalhi, 2009. Hepatoprotective potential of crocin and curcumin against iron overload-induced biochemical alterations in rat. Afr. J. Biochem. Res., 3: 215-221.

Esterbauer, H. and K.H. Cheeseman, 1990. Determination of aldehydic lipid peroxidation products: Malonaldehyde and 4-hydroxynonenal. Methods Enzymol., 186: 407-421.

Farrell, G.C., 2003. Non-alcoholic steatohepatitis: What is it and why is it important in the Asia-Pacific region?. J. Gastroenterol. Hepatol., 18: 124-138. 
He, S.Y., Z.Y. Qian, F.T. Tang, N. Wen, G.L. Xu and L. Sheng, 2005. Effect of crocin on experimental atherosclerosis in quails and its mechanisms. Life Sci., 77: 907-921.

Hokanson, J.E., 2002. Hypertriglyceridemia and risk of coronary heart disease. Curr. Cardiol. Rep., 4: 488-493.

Hosseinzadeh, H., F. Shamsaie and S. Mehri, 2009. Antioxidant activity of aqueous and ethanolic extracts of Crocus sativus L. stigma and its bioactive constituents, crocin and safranal. Pharm. Mag., 5: 419-424.

James, O. and C. Day, 1999. Non-alcoholic steatohepatitis: Another disease of affluence. Lancet, 353: 1634-1636.

Kakkar, P., B. Das andP.N. Viswanathan, 1984. A modified spectrophotometric assay of superoxide dismutase. Ind. J. Biochem. Biophys., 21: 130-132.

Kametani, T., H. Koshida, T. Nagaoka and H. Miyakoshi, 2002. Hypertriglyceridemia is an independent risk factor for development of impaired fasting glucose and diabetes mellitus: A 9-year longitudinal study in Japanese. Internet Med., 41 : 516-521.

Koteish, A. and A.M. Diehl, 2002. Animal models of steatohepatitis. Best Prac. Res. Clin. Gastroenterol., 16: 679-690.

Lee, G. and H.T. Luna, 1968. Manual of Histologic Staining Methods of the Armed Forces Institute of Pathology. 3rd Edn., McGraw Hill Book Co., New York, pp: 32-37.

Lowry, O.H., N.J. Rosebrough, A.L. Farr and R.J. Randall, 1951. Protein measurement with the Folin phenol reagent. J. Biol. Chem., 193: 265-275.

Magesh, V., J. Prince Vijeya Singh, K. Selvendiran, G. Ekambaram and D. Sakthisekaran, 2006. Antitumour activity of crocetin in accordance to tumor incidence, antioxidant status, drug metabolizing enzymes and histopathological studies. Mol. Cell Biol., 287: 127-135.

Malloy, H.T. and K.A. Evelyn, 1937. The determination of bilirubin level with the photoelectric colorimeter. J. Biol. Chem., 119: 481-484.

Martinek, R.G., 1972. A rapid ultraviolet spectrophotometric lactic dehydrogenase assay. Clin. Chem. Acta, 40: 91-99.

Mohandas, J., J.J. Marshall, G.G. Duggin, J.S. Horvath and D.J. Tiller, 1984. Low activities of glutathione-related enzymes as factors in the genesis of urinary bladder cancer. Cancer Res., 44: 5086-5091.

Nishikimi, M., N.A. Rao and K. Yagi, 1972. The occurrence of superoxide anion in the reaction of reduced phenazine methosulfate and molecular oxygen. Biochem. Biophys. Res. Commun., 46: 849-854.
Ochiai, T., S. Ohno, S. Soeda, H. Tanaka, Y. Shoyama and H. Shimeno, 2004. Crocin prevents the death of rat pheochromyctoma (PC-12) cells by its antioxidant effects stronger than those of $\alpha$-tocopherol. Neurosci. Lett., 362: 61-64.

Orrenius S., V. Gogvadze and B. Zhivotovsky, 2007. Mitochondrial oxidative stress: Implications for cell death. Ann. Rev. Pharmacol. Toxicol., 47: 143-183.

Postic, C. and J. Girard, 2008. Contribution of de novo fatty acid synthesis to hepatic steatosis and insulin resistance: Lessons from genetically engineered mice. J. Clin. Invest., 118: 829-838.

Reitman, S. and S. Frankel, 1957. A colorimetric method for the determination of serum glutamic oxaloacetic and glutamic pyruvic transaminase. Am. J. Clin. Pathol., 28: 56-63.

Rotruck, J.T., A.L. Pope, H.E. Ganther, A.B. Swanson, D.G. Hafeman and W.G. Hoekstra, 1973. Selenium: Biochemical role as a component of glutathione peroxidase. Sci., 179: 588-590.

Shen, X., Y. Tang, R. Yang, L. Yu, T. Fang and J.A. Duan, 2009. The protective effect of Zizyphus jujube fruit on carbon tetrachloride-induced hepatic injury in mice by anti-oxidative activities. J. Ethanopharmacol., 122: $555-560$.

Shen, X.C. and Z.Y. Qian, 2006. Effects of crocetin on antioxidant enzymatic activities in cardiac hypertrophy induced by norepinephrine in rats. Pharmazie, 61: 348-352.

Sheng, L., Z. Qian, S. Zheng and L. Xi, 2006. Mechanism of hypolipidemic effect of crocin in rats: Crocin inhibits pancreatic lipase. Eur. J. Pharmacol., 543: 116-122.

Tseng, T.H., C.Y. Chu, J.M. Huang, S.J. Shiow and C.J. Wang, 1995. Crocetin protects against oxidative damage in rat primary hepatocytes. Cancer Lett., 97: 61-67.

Walldius, G., A. Aastveit and I. Jungner, 2004. Hypercholesterolemia and hypertriglyceridemiagreatest cardiac risk in subjects with high apoB/apoA-I levels. Int. Cong. Ser., 1262: 203-206.

Wang, J.Q., J. Li, Y.H. Zou, W.M. Cheng and C. Lu et al., 2009. Preventive effects of total flavonoids of Litsea coreana leve on hepatic steatosis in rats fed with high fat diet. J. Ethnopharmacol., 121: 54-60.

Xiang, M., Z.Y. Qian, C.H. Zhou, J. Liu and W.N. Li, 2006. Crocetin inhibits leukocyte adherence to vascular endothelial cells induced by AGEs. J. Ethnopharmacol., 107: 25-31.

Zou, Y., J. Li, C. Lu, J. Wang and J. Ge et al., 2006. High-fat emulsion-induced rat model of nonalcoholic steatohepatitis. Life Sci., 79: 1100-1107. 